\title{
Cropping systems modify soil biota effects on wheat (Triticum aestivum) growth and competitive ability
}

\author{
Authors: Stephen P. Johnson, Zach J. Miller, Erik A. \\ Lehnhoff, Perry R. Miller, and Fabian D. Menalled
}

This is the peer reviewed version of the following article: Johnson, Stephen P. , Zach J. Miller, Erik A. Lehnhoff, Perry R. Miller, and Fabian D. Menalled. "Cropping systems modify soil biota effects on wheat (Triticum aestivum) growth and competitive ability."Weed Research 57, no. 1 (February 2017): 6-15. DOI: 10.1111/wre.12231, which has been published in final form at https://dx.doi.org/10.1111/wre.12231. This article may be used for non-commercial purposes in accordance with Wiley Terms and Conditions for Self-Archiving.

Johnson, Stephen P. , Zach J. Miller, Erik A. Lehnhoff, Perry R. Miller, and Fabian D. Menalled. "Cropping systems modify soil biota effects on wheat (Triticum aestivum) growth and competitive ability." Weed Research 57, no. 1 (February 2017): 6-15. DOI: 10.1111/wre.12231.

Made available through Montana State University's $\underline{\text { ScholarWorks }}$ scholarworks. montana.edu 


\title{
Cropping systems modify soil biota effects on wheat (Triticum aestivum) growth and competitive ability
}

\author{
Stephen P. Johnson ${ }^{1}$, Zach J. Miller ${ }^{2}$, Erik A. Lehnhoff ${ }^{3}$, Perry R. Miller ${ }^{1}$, and Fabian D. Menalled ${ }^{1}$ \\ ${ }^{1}$ Department of Land Resources and Environmental Sciences, Montana State University, Bozeman, MT, USA, \\ ${ }^{2}$ Research Center, Montana State University, Corvallis, MT, USA, \\ ${ }^{3}$ Department of Entomology, Plant Pathology and Weed Science, New Mexico State University, Las Cruces, NM, USA
}

\section{Summary}

Plants alter soil biota which subsequently modifies plant growth, plant-plant interactions and plant community dynamics. While much research has been conducted on the magnitude and importance of soil biota effects (SBEs) in natural systems, little is known in agro-ecosystems. We investigated whether agricultural management systems could affect SBEs impacts on crop growth and crop-weed competition. Utilising soil collected from eight paired farms, we evaluated the extent to which SBEs differed between conventional and organic farming systems. Soils were conditioned by growing two common annual weeds: Amaranthus retroflexus (redroot pigweed) or Avena fatua (wild oat). Soil biota effects were measured in wheat (Triticum aestivum) growth and crop-weed competition, with SBEs calculated as the natural log of plant biomass in pots inoculated with living soil divided by the

\section{Introduction}

Recent research has increased our understanding of the mechanisms by which plants alter nutrient availability (Ehrenfeld et al., 2005), soil moisture (Nielsen et al., 2005) and soil biota (Wolfe \& Klironomos, plant biomass in pots inoculated with sterilised soil. SBEs were generally more positive when soil inoculum was collected from organic farms compared with conventional farms, suggesting that cropping systems modify the relative abundance of mutualistic and pathogenic organisms responsible for the observed SBEs. Also, as feedbacks became more positive, cropweed competition decreased and facilitation increased. In annual cropping systems, SBEs can alter plant growth and crop-weed competition. By identifying the management practices that promote positive SBEs, producers can minimise the impacts of crop-weed competition and decrease their reliance on off-farm chemical and mechanical inputs to control weeds, enhancing agroecosystem sustainability.

Keywords: conventional agriculture, crop-weed competition, diversification, organic agriculture, plant-soil feedbacks, weeds, wheat-fallow.
2005) and how these, in turn, modify interactions with organisms at the same or different trophic levels (Hol et al., 2013). Despite this knowledge, weed science has been primarily focused on developing chemical and mechanical methods to minimise weed abundances, rather than assessing the mechanisms driving 
crop-weed competitive interactions (Ward et al., 2014). While this approach to weed management has helped to improve yields and farm labour efficiencies, it has known drawbacks including soil erosion from tillage (Greer et al., 2006), soil and ground water contamination from pesticides (Van Oost et al., 2005) and the evolution of herbicide resistant weeds (Powles \& Yu, 2010).

New societal concerns, as well as climate, policy and market challenges, require weed science to address the ecological principles underlying complex issues in weed management (Davis et al., 2009). In this context, Smith et al. (2010) proposed the Resource Pool Diversity Hypothesis to explain how the soil resource pool, a function of soil microbial communities (Reynolds et al., 2003), and cropping system diversity may mediate crop-weed competitive interactions. The Resource Pool Diversity Hypothesis proposes that cropping system diversification results in increased niche differentiation and resource partitioning which, in turn, translates to reduced yield loss from crop-weed competition. In accordance, Ryan et al. $(2009,2010)$ provide empirical evidence that under increased cropping system diversification, crop-weed competition is less intense.

Crop-weed interactions may be at least partially explained through the impact of plant growth on soil biota effects (SBEs) (Brinkman et al., 2010), where management practices such as tillage, cropping system diversification and cover cropping alter soil microbial communities (Wortman et al., 2013), and these alterations in turn may impact the growth of plants that subsequently occupy that site (Wardle et al., 2004). Recently, interest has risen regarding the potential role of these biologically mediated feedbacks in determining crop and weed growth (Smith et al., 2011; Miller \& Menalled, 2015) as well as crop-weed competitive interactions (Hol et al., 2013). While organically managed systems typically have a greater abundance and diversity of weeds than conventionally managed ones (Menalled et al., 2001; Pollnac et al., 2009), yield loss in organic fields is often not commensurate with weed abundance (Davis et al., 2005; Ryan et al., 2009; Smith et al., 2010), suggesting that crops in organic systems exhibit greater tolerance to weeds. Is it possible that through their impacts on SBEs, cropping systems are responsible for the increased tolerance to weed-crop competition observed in organic systems when compared to conventional ones? In this study, we evaluated the extent to which the differential SBEs that occur in organic and conventional cropping systems could modify (i) wheat growth and (ii) wheat competitive interactions with weeds.

\section{Materials and methods}

\section{Soil collection}

Eight paired USDA-certified organic and conventional farms located in north-central Montana were sampled in July 2013 to obtain the soil inocula used in our glasshouse experiment (see Fig. S1). Paired farms were located on average $3.3 \mathrm{~km}(\mathrm{SD}=4.5)$ apart from each other, with pairs distributed across a broad region (mean distance between pairs $137 \mathrm{~km}, \mathrm{SD}=40$ ). Conventional farms all practiced a no-tillage wheat-fallow rotation, and organic farms had been managed for at least 5 years with tillage intensive, diverse crop rotations that included legumes and multiple grain species (see Table S1). Sampled fields could not be randomly selected because of logistical constraints, including the need for farms to be paired, sampled fields being planted to a wheat crop [except the organic Dutton location planted to Triticum turanicum Jakubz. (var. Kamut), a close relative of wheat] and obtaining landowner permission for soil collection. Despite these limitations, sampled fields represented a wide range of soil characteristics (loams, clay loams and silty clay loams), temperatures (mean max. of $12.9-14.8^{\circ} \mathrm{C}$; mean min. $\left(-2.7\right.$ to $\left.-0.9^{\circ} \mathrm{C}\right)$ and annual precipitation (265-388 mm) (see Table S1).

Within each field, soil was collected to a depth of $13 \mathrm{~cm}$ via $6 \mathrm{~cm}$ diameter cores every $10 \mathrm{~m}$ along a 200-m W-shaped transect, for a total of 21 subsamples per transect, to reflect the spatial heterogeneity of the fields. Transects were located at least $100 \mathrm{~m}$ from any field edge and positioned on relatively uniform slopes. Subsamples were pooled into one sample per field, and all soil was refrigerated at $4^{\circ} \mathrm{C}$ until the experiments began. Prior to commencing the experiment, the soils were air-dried for 2 weeks and sifted through a $1 \mathrm{~cm}^{2}$ sieve. To isolate the effects of soil biotic communities, each soil sample was split. Half the soil was heated to $120^{\circ} \mathrm{C}$ for two 1 -h periods with $24 \mathrm{~h}$ between treatments (sterilised, hereafter). Half was left unsterilised (biologically active, hereafter).

\section{Experimental design}

This study was conducted at Montana State University, Bozeman, MT. The potting media used was a steam pasteurised $\left(70^{\circ} \mathrm{C}\right.$ for $\left.4 \mathrm{~h}\right)$ glasshouse soil mix with equal parts by volume of loam soil, washed concrete sand and Canadian sphagnum peat moss, with AquaGro $2000 \mathrm{G}$ wetting agent blended at $0.59 \mathrm{~kg} \mathrm{~m}^{-3}$. Pots $(2.5 \mathrm{~L}$ volume, $18 \mathrm{~cm}$ diameter $\times 14 \mathrm{~cm}$ height) were filled with the potting media and individually inoculated with a small amount 
( $80 \mathrm{~mL}$, approximately $3.5 \%$ by volume) of either a biologically active or sterilised soil inoculum collected from one farm. For each pot, the inoculum was incorporated into the potting media.

The experiment was replicated simultaneously in two separate glasshouses under a 16-h photoperiod of natural sunlight supplemented with mercury vapour lamps $\left(165 \mu \mathrm{E} \mathrm{m}^{-2} \mathrm{~s}^{-1}\right)$ at $22^{\circ} \mathrm{C} / 18^{\circ} \mathrm{C}$ day/night. Within each glasshouse, pots were arranged following a randomised block design with three replicated blocks per glasshouse. This experiment followed a two phase design: a conditioning phase and a response phase. The conditioning phase allowed either Amaranthus retroflexus L. (redroot pigweed, a dicotyledon) or Avena fatua L. (wild oat, a monocotyledon) growth to alter the soil biotic community in species-specific ways. These weed species are common and problematic in grain growing regions of North America, Asia, Europe and Australia and were chosen due to their abundance in organic and conventional fields in Montana (Pollnac et al., 2008, 2009). The response phase assessed the relative impact of farming system (conventional or organic), type of inoculum (biologically active or sterile) and conditioning species identity (A. retroflexus or $A$. fatua) on the growth and competitiveness of wheat. In total, this study comprised 576 pots $(N=8$ farms $\times 2$ inocula $\times 2$ conditioning species $\times 3$ response treatments $\times 2$ glasshouses $\times 3$ replicates per glasshouse $=576$ ) .

The conditioning phase consisted of two-eight-week growing periods, where individual pots were seeded with either an average of 60 A. retroflexus seeds or 12 A. fatua seeds (seeds locally collected, Bozeman, MT) and thinned 10 days after emergence to either ten or six evenly spaced individuals respectively. Two conditioning phases were used to provide additional time for the proliferation of the microbial communities, and the two growing periods were separated by a 2week period. The different numbers of A. retroflexus and $A$. fatua seedlings were to obtain approximately similar biomasses of the two species. Pots were watered using tap water as necessary and were not fertilised during the conditioning phase, as fertilisation often changes soil biota dynamics (Marschner, 2003), including varying effects on mycorrhizal, pathogenic and saprophytic microorganisms (Brinkman et al., 2010). Plant biomass (above ground only; roots were left in the pots after each growing period) was calculated from the combined total of both conditioning periods, dried to a constant weight in an oven at $40^{\circ} \mathrm{C}$ and weighed to the nearest $0.01 \mathrm{~g}$. Soil samples $(10 \mathrm{~cm}$ depth $\times 1 \mathrm{~cm}$ diameter) were collected at the end of the conditioning phase from 192 pots, representing six replicates per conditioning phase treatment for each inoculum source (locality, and conventional or organic) and analysed for concentrations of $\mathrm{NO}_{3}^{-}$, Olsen/Bray $\mathrm{P}$ and $\mathrm{K}$ by Agvise Laboratories (Northwood, ND).

After the second conditioning phase, pots were randomly assigned to one of three response phase treatments (competitive status): (i) wheat grown in monoculture, or wheat in competition with either (ii) A. fatua or (iii) A. retroflexus. Six wheat seeds were planted in each pot with two seeds at three locations. The competition treatment consisted of either twelve $A$. fatua seeds evenly spaced in six locations in between the wheat or approximately 60 seeds of $A$. retroflexus seeds evenly spaced in nine locations between the wheat. Seedlings were thinned 10 days after emergence to three, six or nine individuals for wheat, A. fatua and $A$. retroflexus respectively. As before, pots were watered as necessary and were not fertilised. Eight weeks after seeding, all above ground plant biomass was harvested, separated by species, dried and weighed as above.

\section{Statistical analyses}

We tested the effects of SBEs from organic and conventional soils as conditioned by $A$. fatua and A. retroflexus as follows:

$$
\begin{aligned}
& \mathrm{SBE}_{i j k l m}= \\
& \ln \frac{\text { plant biomass }}{\text { plant biomass }} \text { ijklm pots inoculated with living soil } \\
& \text { inoculated with sterlized soil }
\end{aligned}
$$

where biomass ${ }_{i j k l m}$ represents the biomass for the competitive status treatment $i$, grown in the response phase and conditioned by species $j$, soil inoculum source $k$ and block $l$ within each glasshouse trial $m$. This metric is centred on zero when the plant biomass in pots receiving a biologically active inoculum is equal to the biomass in pots receiving a sterilised inoculum. SBE values are positive when plant biomass is greater in pots that received the biologically active inoculum, and negative when plant biomass is greater in pots that received a sterilised inoculum. Results are presented in terms of both SBEs and biomass, as recommended by Brinkman et al. (2010).

We fitted linear mixed-effects regression models to evaluate differences in biomass and SBE responses considering locality a random effect and accounted for locality differences by nesting farming system (conventional or organic) within localities and inoculum type (sterile or biologically active) within farming system. Farming system, conditioning species identity, competitive status and inoculum type were included as fixed effects. We also included $\mathrm{NO}_{3}^{-}$, Olsen/Bray $\mathrm{P}$, 
$\mathrm{K}$ and combined biomass sampled at the end of the conditioning phase as covariates. Model selection was accomplished using likelihood ratio tests to calculate chi-square statistics comparing the full model with the explanatory variable in question against a model without that variable. We started with a saturated model that included all explanatory variables and interactions and used a stepwise procedure to find the optimal random slope structure for each random intercept under restricted maximum likelihood (Barr et al., 2013). We then used maximum-likelihood estimation and a backwards stepwise procedure to test the fixed effects and repeated this process until no additional explanatory variables could be removed. To assess differences in the strength of SBEs among competitive status treatments, we included an interaction term between farming system and competitive status. Confidence intervals and planned comparisons under each competition scenario were made using least squares means and Satterthwaite's approximation of degrees of freedom. Normality and equality of variances were visually evaluated using residual plots. Weed biomass values in the response phase were natural log-transformed to improve normality and homogeneity of variances. Wheat biomass values did not require transformations.

To assess the impact of SBEs on competitive interactions, we evaluated differences in the intensity of competition using the log response ratio (lnRR) (Goldberg et al., 1999):

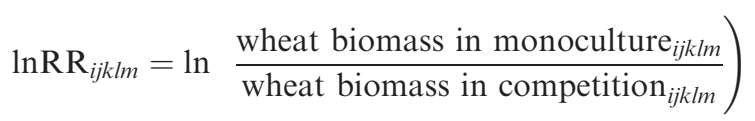

where $\ln \mathrm{RR}_{i j k l m}$ represents the $\log$ response ratio for competitive status treatment $i$ at the combination of conditioning species identity $j$, soil inoculum source $k$ and block $l$ within each glasshouse trial $m$. The log response ratio is centred on zero, allowing us to test for linear relationships in the intensity of competition $(\operatorname{lnRR}>0)$ or facilitation $(\operatorname{lnRR}<0)(O k s a n e n$ et al., 2006). We used this index to evaluate whether the intensity of weed competition with T. aestivum in biologically active inoculated pots varied between organic and conventional systems and whether it depended on the strength of the SBE. Weed biomass values were log-transformed to better satisfy model assumptions.

We used ' $\mathrm{R}$ ' statistical software ( $\mathrm{R}$ Core Team, 2013) for analysis, package 'Ime4' (Bates et al., 2014) to fit linear mixed-effect models, package 'sciplot' to build bargraphs, package 'ggplot2' (Wickham, 2009) to build regression plots and package 'ImerTest' (Kuznetsova et al., 2014) for least squares means comparisons, confidence interval estimates and inferences about regression coefficients.

\section{Results}

\section{Impact of conditioning phase biomass and nutrient status on response phase plant growth}

There was no evidence of a relationship between the biomass produced during the conditioning phase and the biomass harvested at the end of the response phase for wheat $(P=0.610), \quad$ A. retroflexus $(P=0.495)$ or A. fatua $(P=0.367)$, regardless of inoculum source or type, conditioning species identity or competitive status. Therefore, conditioning phase biomass was excluded as a covariate from all further analyses. The inclusion of Olsen/Bray $\mathrm{P}$ or $\mathrm{K}$ as covariates of the wheat biomass harvested at the end of the response phase increased the model deviance, indicating that these variables did not help explain the observed results. As expected, there was a positive relationship between $\mathrm{NO}_{3}^{-}$concentration at the end of the conditioning phases and wheat biomass harvested during the response phase $(P=0.001)$. Pots that received the biologically active inoculum had 1.73 times more $\mathrm{NO}_{3}^{-}$available than those receiving the sterilised inoculum $(95 \% \mathrm{CI}=1.47-1.99)$ and $\mathrm{NO}_{3}^{-}$ levels were similar between farming systems $\left[\chi^{2}\right.$ (1) $=1.5575, P=0.21]$. While pots that had received a biologically active inoculum and were conditioned by $A$. retroflexus had 1.58 times more $\mathrm{NO}_{3}^{-} \quad(95 \%$ $\mathrm{CI}=1.32-1.84)$ than those conditioned by A. fatua, there were no differences in $\mathrm{NO}_{3}^{-}$levels between conditioning species in pots that received sterile inoculum $(P=0.525)$, resulting in an interaction between inoculum type and conditioning species identity $\left[\chi^{2}\right.$ $(1)=10.156, P=0.001]$.

\section{Weed growth and weed responses to soil biota effects}

During the response phase, the identity of the conditioning phase species impacted A. fatua and A. retroflexus growth differently depending on the inoculum type (Table 1a,b). Also, the effect of farming system on $A$. retroflexus growth depended on the inoculum type (Table 1 b). Pots with biologically active inoculum produced more plant biomass than did those with a sterilised inoculum, regardless of the inoculum source (Fig. 1A-D). In biologically active soils, A. fat$u a$ grew 1.24 times more biomass $(95 \%$ C.I. $=1.03-$ 1.45) when conditioned by $A$. retroflexus compared with $A$. fatua-conditioned soils, but no differences were 
Table 1 Impact of conditioning species identity, farming systems, inoculum type, competitive status and their interactions on (a) Avena fatua, (b) Amaranthus retroflexus or (c) wheat (Triticum aestivum) biomass of plants growing in pots that received either a sterilised inoculum or biologically active inoculum

\begin{tabular}{|c|c|c|c|c|c|c|}
\hline Source & Df & logLik & Deviance & Chisq & Chi Df & $P(>$ Chisq $)$ \\
\hline \multicolumn{7}{|l|}{ (a) } \\
\hline Farming system (S) & 10 & -62.02 & 124.04 & 1.91 & 1 & 0.17 \\
\hline Conditioning phase spp. (C)*1 & 10 & -63.45 & 126.90 & 4.77 & 1 & 0.029 \\
\hline S*Inoculum type (I) & 11 & -61.07 & 122.13 & 0.20 & 1 & 0.66 \\
\hline $\mathrm{S} * \mathrm{C}$ & 12 & -60.97 & 121.93 & 1.86 & 1 & 0.17 \\
\hline $\mathrm{S} * \mathrm{C} * \mathrm{I}$ & 13 & -60.04 & 120.07 & 3.11 & 1 & 0.078 \\
\hline Saturated model & 14 & -58.48 & 116.96 & & & \\
\hline \multicolumn{7}{|l|}{ (b) } \\
\hline$C * I$ & 11 & -184.70 & 369.39 & 18.15 & 1 & $<0.0001$ \\
\hline $\mathrm{S} * \mathrm{I}$ & 11 & -178.96 & 357.93 & 6.69 & 1 & 0.0097 \\
\hline $\mathrm{S} * \mathrm{C}$ & 12 & -175.62 & 351.24 & 0.02 & 1 & 0.89 \\
\hline $\mathrm{S} * \mathrm{C} * \mathrm{I}$ & 13 & -175.61 & 351.22 & 0.17 & 1 & 0.68 \\
\hline Saturated model & 14 & -175.52 & 351.05 & & & \\
\hline \multicolumn{7}{|l|}{ (c) } \\
\hline$C * 1$ & 15 & 326.95 & -653.89 & 6.59 & 1 & 0.010 \\
\hline Competitive status $(\mathrm{R}) * \mathrm{I}$ & 14 & 317.47 & -634.95 & 25.54 & 2 & $<0.0001$ \\
\hline $\mathrm{S} * \mathrm{I}$ & 15 & 327.21 & -654.42 & 6.06 & 1 & 0.014 \\
\hline $\mathrm{S} * \mathrm{C}$ & 16 & 330.24 & -660.48 & 2.87 & 1 & 0.090 \\
\hline $\mathrm{R} * \mathrm{C}$ & 17 & 331.68 & -663.35 & 0.41 & 2 & 0.81 \\
\hline $\mathrm{S} * \mathrm{R}$ & 19 & 331.88 & -663.76 & 2.27 & 2 & 0.32 \\
\hline $\mathrm{R} * \mathrm{C} * \mathrm{I}$ & 21 & 333.01 & -666.03 & 1.44 & 2 & 0.49 \\
\hline $\mathrm{S} * \mathrm{C} * 1$ & 23 & 333.74 & -667.47 & 1.08 & 1 & 0.30 \\
\hline $\mathrm{S} * \mathrm{R} * 1$ & 24 & 334.27 & -668.55 & 2.98 & 2 & 0.23 \\
\hline $\mathrm{S} * \mathrm{R} * \mathrm{C}$ & 26 & 335.76 & -671.52 & 2.00 & 2 & 0.37 \\
\hline $\mathrm{S} * \mathrm{C} * \mathrm{R} * \mathrm{I}$ & 28 & 336.76 & -673.52 & 0.15 & 2 & 0.93 \\
\hline Saturated model & 30 & 336.84 & -673.68 & & & \\
\hline
\end{tabular}

Data were analysed with a likelihood ratio tests using backwards elimination. The saturated model includes all possible main effects and interactions.
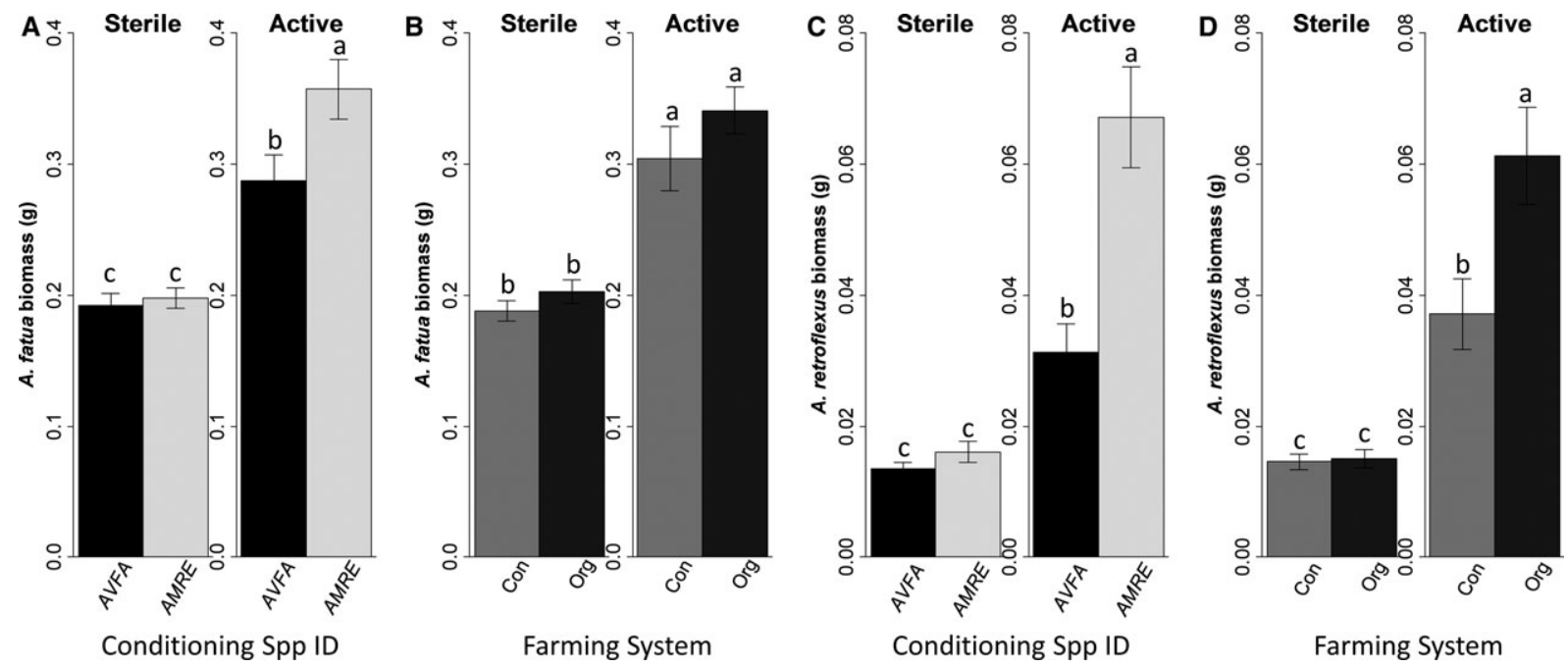

Fig. 1 Biomass (mean $\pm \mathrm{SE}$ ) produced during the response phase in pots that received either a sterile or biologically active inoculum. Avena fatua biomass as a function of conditioning species identity (A) and farming system (B); Amaranthus retroflexus biomass as a function of conditioning species identity $(\mathrm{C})$ and farming system $(\mathrm{D})$. Letters indicate differences $(P<0.05)$. Comparisons were made on natural $\log$-transformed data for $A$. fatua and $A$. retroflexus, but raw data are presented. Con $=$ conventional and Org $=$ organic. $\mathrm{AVFA}=A$. fatua and $\mathrm{AMRE}=$ A. retroflexus. For clarity, only significant comparisons are shown.

observed between conditioning species treatments in sterilised treatments (Fig. 1A). There was no effect of farming system on A. fatua growth, regardless of inoculum type, with differences found only between inocula type (Fig. 1B). In biologically active soils, A. retroflexus grew 2.15 times more biomass $(95 \%$ 
C.I. $=1.27-3.0$.) when conditioned by conspecifics, yet no differences were found in sterile inoculated treatments (Fig. 1C). Further, A. retroflexus grown in biologically active soils from organic farms grew 1.63 times more biomass $(95 \%$ C.I. $=1.42-1.84)$ than from conventional farm soils, but the inoculum source had no impact on weed growth in sterilised treatments (Fig. 1D).

In accordance with the biomass results, SBEs observed in $A$. fatua were 1.64 times more positive $(95 \%$ C.I. $=0.92-2.36)$ following heterospecific than conspecific growth, but there was no evidence that SBEs differed between farming systems (Table 2a). For A. retroflexus, species identity during the conditioning phase and farming systems altered SBEs, with no interactions between these variables (Table 2b). Specifically, A. retroflexus SBEs were 2.32 times more positive $(95 \% \mathrm{CI}=1.60-3.04)$ in conspecific conditioned soils versus $A$. fatua-conditioned soils. In addition, A. retroflexus SBEs observed in pots that had received the inoculum collected from organic farms were 2.17 times more positive $(95 \%$ C.I. $=1.51-2.83)$ than those from conventional farms.

\section{Wheat growth and responses to soil biota effects}

During the response phase, the conditioning phase species identity, competitive status treatments and effect of farming system all interacted with the inoculum type in determining wheat biomass (Table 1c). Competition with Avena fatua reduced wheat biomass by $27 \%$ $(95 \%$ C.I. $=18-35 \%)$ in pots that had received a biologically active inoculum, yet sterilised inoculated treatments showed no difference (Fig. 2A). Amaranthus retroflexus did not affect wheat biomass $(95 \%$ C.I. $=-7-10 \%$ ), when compared with the wheat monoculture (Fig. 2A). Regardless of conditioning species identity or response phase competitive status, wheat always grew more biomass in soils that received a biologically active inoculum collected from organic farms, with biomass $31 \% \quad(95 \% \quad$ C.I. $=14-48 \%)$ greater than those plants that received inoculum collected from a conventional farm (Fig. 2B). An evaluation of the extent to which competitive status interacted with farming system in determining wheat biomass (Fig. 2C) indicated that competition with A. fatua, but not A. retroflexus, resulted in lower wheat biomass. Moreover, the strength of the competitive interactions varied between organic and conventional systems. In pots where wheat competed with A. fatua or A.retroflexus, wheat biomass was, respectively, 1.27 times $(95 \%$ C.I. $=1.17-1.37)$ and 1.41 $(95 \%$ C.I. $=1.31-1.51)$ times greater in pots receiving inoculum from organic farms compared with conventional farms. Furthermore, wheat biomass in pots receiving inocula from organic farms and in competition with A. fatua was similar to the wheat monoculture biomass in pots inoculated with conventional farm soil.

Table 2 Impact of conditioning species identity, farming systems, competitive status and their interactions on soil biotic effects (SBEs) observed on (a) Avena fatua, (b) Amaranthus retroflexus or (c) Triticum aestivum

\begin{tabular}{|c|c|c|c|c|c|c|}
\hline Source & Df & logLik & Deviance & Chisq & Chi Df & $P$ (>Chisq) \\
\hline \multicolumn{7}{|l|}{ (a) } \\
\hline Conditioning phase spp. (C) & 7 & -59.65 & 119.31 & 5.68 & 1 & 0.017 \\
\hline Farming system (S) & 7 & -56.94 & 113.89 & 0.26 & 1 & 0.61 \\
\hline $\mathrm{S} * \mathrm{C}$ & 8 & -56.82 & 113.63 & 2.88 & 1 & 0.090 \\
\hline $\begin{array}{l}\text { Saturated model } \\
\text { (b) }\end{array}$ & 9 & -55.38 & 110.75 & & & \\
\hline Conditioning phase spp. (C) & 7 & -124.76 & 249.53 & 17.40 & 1 & $<0.0001$ \\
\hline Farming system (S) & 7 & -118.85 & 237.70 & 5.57 & 1 & 0.018 \\
\hline $\mathrm{S} * \mathrm{C}$ & 8 & -116.06 & 232.13 & 0.08 & 1 & 0.78 \\
\hline $\begin{array}{l}\text { Saturated model } \\
\text { (c) }\end{array}$ & 9 & -116.02 & 232.05 & & & \\
\hline Conditioning phase spp. (C) & 9 & -197.27 & 394.54 & 0.30 & 1 & 0.59 \\
\hline Competitive status (R) & 8 & -205.67 & 411.35 & 17.10 & 2 & 0.0002 \\
\hline Farming system (S) & 9 & -202.27 & 404.53 & 10.29 & 1 & 0.0013 \\
\hline $\mathrm{R} * \mathrm{C}$ & 10 & -197.12 & 393.25 & 0.98 & 2 & 0.61 \\
\hline $\mathrm{S} * \mathrm{C}$ & 12 & -196.63 & 393.27 & 0.23 & 1 & 0.63 \\
\hline $\mathrm{S} * \mathrm{R}$ & 13 & -196.52 & 393.03 & 2.23 & 2 & 0.33 \\
\hline $\mathrm{S} * \mathrm{C} * \mathrm{R}$ & 15 & -195.40 & 390.81 & 0.41 & 2 & 0.81 \\
\hline Saturated model & 17 & -195.20 & 390.39 & & & \\
\hline
\end{tabular}

Data were analysed with a likelihood ratio tests using backwards elimination. The saturated model includes all possible main effects and interactions. 

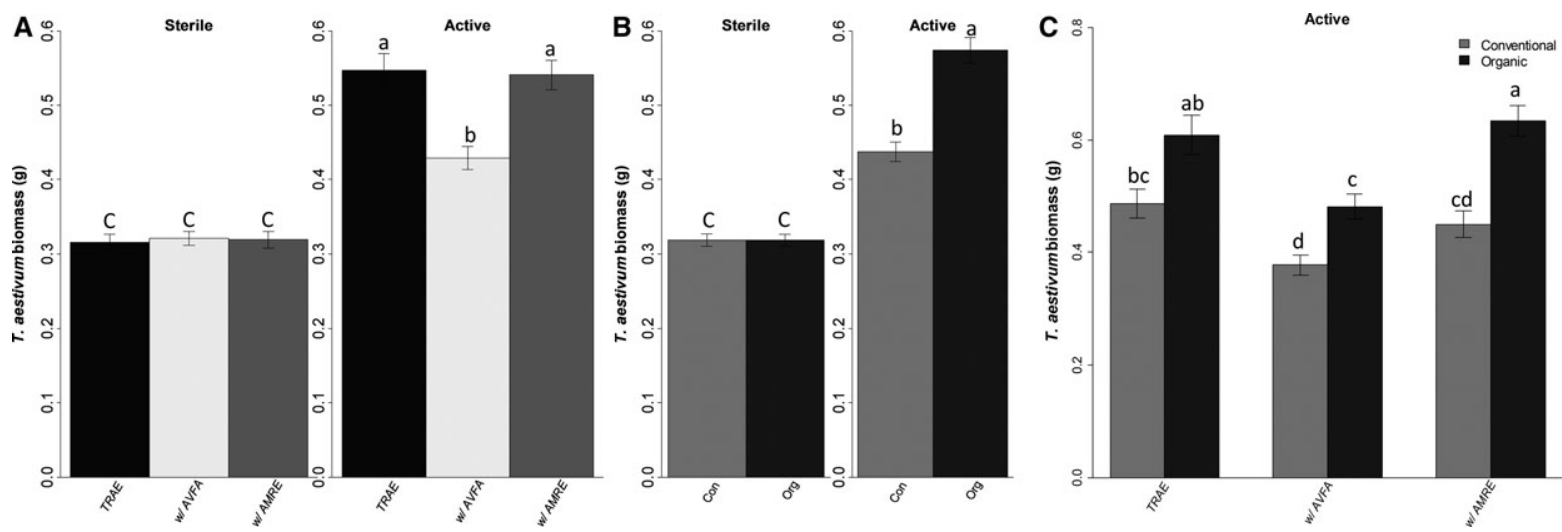

Fig. 2 Wheat (Triticum aestivum, TRAE) biomass (mean $\pm \mathrm{SE}$ ) observed during the response phase as functions of competitive status treatments (A), farming systems (B) and the interactions $(\mathrm{C})$. Letters indicate differences $(P<0.05)$. Con $=$ conventional and Org $=$ organic. AVFA = Avena fatua and AMRE = Amaranthus retroflexus. For clarity, only significant comparisons are shown.

Similar to the biomass results, farming systems and competitive status during the response phase altered SBEs observed in wheat, but no significant effects of conditioning species identity were found (Table 2c). For wheat growing in competition with $A$. fatua, SBEs were $0.79(95 \%$ C.I. $=0.68-0.89)$ times less than when grown in monocultures. In contrast, wheat competing with $A$. retroflexus had similar SBEs as those observed in wheat monocultures. Finally, wheat SBEs were 1.84 times more positive when pots received the inoculum from organic farms when compared with conventional farms $(95 \%$ C.I. $=1.57-2.11)$.

\section{Impact of weeds and SBEs on competitive intensity across cropping systems}

There was no relationship between competitive intensity (i.e. $\operatorname{lnRR})$ and $A$. fatua biomass $(P=0.930, \mathrm{df}=91)$, including no two- or three-way interactions with conditioning species identity or farming system (Fig. 3A). In contrast, for wheat under competition with A. retroflexus, the relationship between competitive intensity and weed biomass depended on the interaction between farming system and conditioning species identity $(P=0.028)$ (Fig. 3B). In $A$. fatua-conditioned soils, there was no evidence of a relationship between competition intensity and A. retroflexus biomass, regardless of farming system (Fig. 3C). In A. retroflexus conditioned soils that had received a conventional farm inoculum, competition intensity increased with higher weed biomass $(P<0.001, \mathrm{df}=85)$, but there was no evidence of this relationship in organic inoculated soils $(P=0.280$, $\mathrm{df}=82)($ Fig 3D).

The relationship between competitive intensity and SBEs did not differ between farming systems or conditioning species identities, regardless of the competitive status treatment (Fig. 3C,D). For the A. fatua competition treatments, the relationship between competitive intensity and SBEs was negative $(P=0.020$, $\mathrm{df}=89$ ). Similarly, there was a strong negative relationship between competitive intensity and SBEs for A. retroflexus competition treatments $(P<0.001$, $\mathrm{df}=86$ ). There were no overall differences for the effects of farming system or conditioning species identity for either competition treatment, and we generally observed shifts from competition $(\ln R R>0)$ to facilitation $(\ln R R<0)$ as SBEs became more positive.

\section{Discussion}

There is growing interest in manipulating farm management practices to enhance soil biological characteristics in ways that positively impact agroecosystems health and services (Brussaard et al., 2007). However, little is known about the impacts of increased cropping system diversification on SBEs and crop-weed interactions. In our study, wheat biomass production was enhanced in pots that were inoculated with biologically active soils, highlighting the importance of soil biota in determining plant growth. Additionally, SBEs were more positive when the biologically active inoculum was collected from organic farms than from conventional farms, suggesting that cropping systems modify the relative abundance of mutualistic (e.g. mycorrhizae) and pathogenic organisms (Matson, 1997). It is also notable that conditioning with $A$. retroflexus produced greater biomass of both A. fatua and A. retroflexus than when soils were conditioned with A. fatua. While this indicates a possible allelopathic effect of $A$. fatua, a more likely explanation is that the higher $\mathrm{NO}_{3}^{-}$levels in A. retroflexus conditioned pots led to greater biomass produced in the response phase.

By isolating the effects of soil biota on plant growth and species interactions, our results provided evidence 

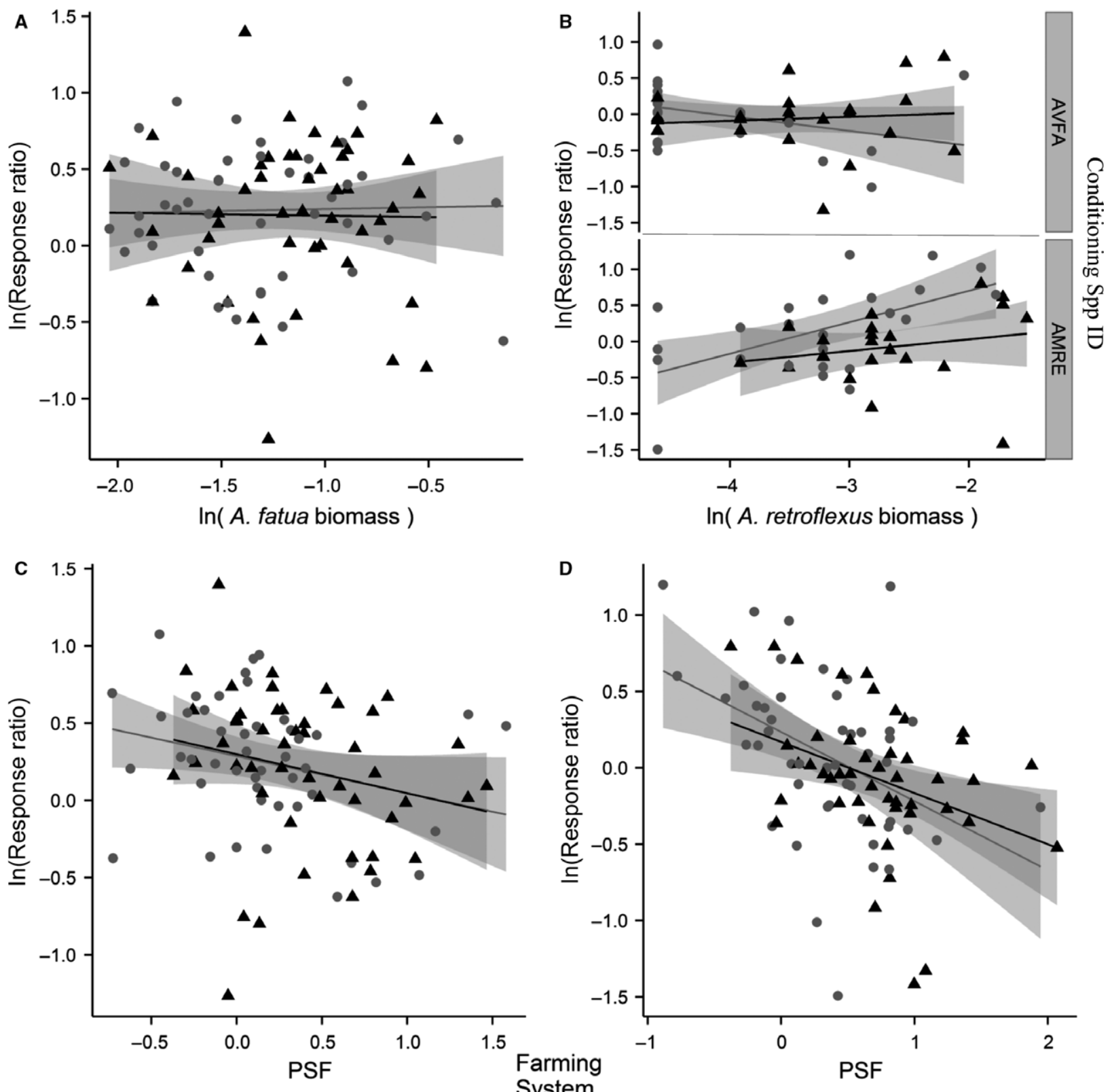

System

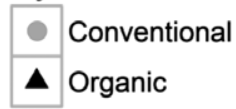

Fig. 3 Regression of wheat (Triticum aestivum) competition intensity (ln RR) with Avena fatua (A) and Amaranthus retroflexus biomass separated by conditioning species treatments (B). Competition intensity and soil biotic effects (SBEs) for wheat in competition with A. fatua (C) and A. retroflexus (D). Competition strength is denoted by the natural logarithm of the response ratio of wheat grown in monoculture compared with wheat grown in competition. Grey shading around the mean lines represents one standard error.

$\mathrm{AMRE}=$ A. retroflexus and $\mathrm{AVFA}=$ A. fatua .

that SBEs translated into an increased ability of wheat to grow in soils that had been inoculated with soil biota from organic farms compared with conventional. Whereas the Resource Pool Diversity Hypothesis (Smith et al., 2010) proposes that diverse cropping rotations mediate crop-weed competition through greater below-ground niche partitioning, our results demonstrate that SBEs can also act as drivers of crop and weed growth as well as competitive interactions in agricultural systems. Therefore, further research is warranted to elucidate the respective roles of diverse resource pools versus SBEs generated through crop diversification in influencing crop growth and cropweed interactions. Regardless, it is important to note that our results are not necessarily the effect of organic versus conventional management practices, per se, but 
probably reflect differences in tillage and the greater crop diversity at the organic farms.

While this study does not allow us to draw conclusions on the specific changes in soil biota responsible for the observed results, it is possible to speculate on the relative impact of management practices associated with organic and conventional farming on the magnitude and impacts of SBEs. Mechanical practices such as tillage, commonly used in organic farming systems, have been associated with a decrease in microbial biomass and earthworm populations (Karlen et al., 1994), as well as a decrease in microbial diversity (Lupwayi et al., 1998). Yet, organic farms often have increased weed diversity (Menalled et al., 2001; Pollnac et al., 2009) and higher plant diversity has been linked with increased microbial biomass (Thakur et al., 2015), respiration and fungal abundance (Zak et al., 2003). On the other hand, agriculture intensification with fertilisers and herbicides, staple practices in no-tillage conventional farming, has a negative impact on meso- and macro-biota in the short term and microbiota over time (Postma-Blaauw et al., 2010). This is in spite of $\mathrm{N}$ addition possibly increasing SBEs (Manning et al., 2008), and is likely mediated through simplified plant communities and long-term loss of organic matter. In our study, crop rotations differed between farming systems, with the organic farms having diverse rotations and the conventional farms all followed wheat-fallow rotations. Previous studies have demonstrated that diverse crop rotations increase the diversity of soil biota (Lupwayi et al., 1998).

The landscape homogeneity of extensive monocultures that characterises conventional industrially managed small grain copping systems has resulted in the development of specialised pest complexes and an associated heavy reliance on off-farm synthetic inputs to control them. Alternatively, encouraging positive biotic interactions, while maintaining acceptable levels of production, is key component of ecologically based cropping systems. Overall, our results show that SBEs can play an important role in mediating plant growth and crop-weed competition in agroecosystems and indicate that diversified organic cropping systems are associated with more positive SBEs. As such, this study suggests that by identifying the management practices that promote positive SBEs for crops and minimise the impacts of crop-weed competition, producers can decrease their reliance on off-farm chemical and mechanical inputs to control weeds and enhance economic and environmental sustainability. Biotic interactions in agroecosystems are complex and future research should explicitly address the mechanisms driving the observed results, including the effects of rotational diversity, weed management technique and weed diversity on soil microbial communities, SBEs and crop-weed competition.

\section{Acknowledgements}

We are grateful to the farmers who allowed us to collect soil samples from their fields. We thank Ali Thornton, Jesse Hunter, Madi Nixon, Ceci Welch and Ethan Mayes who provided assistance with the glasshouse study. Further thanks to Subodh Adhikari, Sean McKenzie and Wyatt Holmes for help gathering soil samples, and Dr. Cathy Zabinski for her insight on below-ground ecology. Finally, we would like to thank the anonymous reviewers whose comments improved this manuscript. This work was partially funded by the USDA-OREI (Grant MONB00365).

\section{References}

Barr DJ, Levy R, Scheepers C \& Tily HJ (2013) Random effects structure for confirmatory hypothesis testing: keep it maximal. Journal of Memory and Language 68, 255-278.

Bates DM, Maechler M, Bolker BM \& Walker S (2014) lme4: models linear mixed-effects eigen using \& S4.

Brinkman PE, van der Putten WH, Bakker EJ \& Verhoeven KJF (2010) Plant-soil feedback: experimental approaches, statistical analyses and ecological interpretations: design and analysis of feedback experiments. Journal of Ecology 98, 1063-1073.

BrussaArd L, De Ruiter PC \& Brown GG (2007) Soil biodiversity for agricultural sustainability. Agriculture Ecosystems and Environment 121, 233-244.

Davis AS, Renner KA \& Gross KL (2005) Weed seedbank and community shifts in a long-term cropping system experiment. Weed Science 53, 296-306.

Davis AS, Hall JC, Jasieniuk M et al. (2009) Weed science research and funding: a call to action. Weed Science $\mathbf{5 7}$, 442-448.

Ehrenfeld JG, Ravit B \& Elgersma K (2005) Feedback in the plant-soil system. Annual Review of Environment and Resources 30, 75-115.

Goldberg De, Rajaniemi T, Gurevitch J \& Stewart-Oaten A (1999) Empirical approaches to quantifying interaction intensity: competition and facilitation along productivity gradients. Ecology 80, 1118-1131.

Greer RC, Wu JQ, Singh P \& McCool DK (2006) WEPP simulation of observed winter runoff and erosion in the U.S. Pacific Northwest. Vadose Zone Journal 5, 261-272.

Hol WHG, de Boer W, ten Hooven F \& van der Putten WH (2013) Competition increases sensitivity of wheat (Triticum aestivum) to biotic plant-soil feedback (ed JF CAHILl) PLoS One 8, e66085.

Karlen DL, Wollenhaupt NC, Erbach DC et al. (1994) Long-term tillage effects on soil quality. Soil Tillage Research 32, 313-327.

Kuznetsova A, Brockhoff PB \& Christensen RHB (2014) lmerTest: Tests for Random and Fixed Effects for Linear Mixed Effects Models (lmer Objects of lme4 Package).

Lupwayi NZ, Rice WA \& Clayton GW (1998) Soil microbial diversity and community structure under wheat 
as influenced by tillage and crop rotation. Soil Biology and Biochemistry 30, 1733-1741.

Manning P, Morrison SA, Bonkowski M \& Bardgett RD (2008) Nitrogen enrichment modifies plant community structure via changes to plant-soil feedback. Oecologia 157, 661-673.

Marschner P (2003) Structure and function of the soil microbial community in a long-term fertilizer experiment. Soil Biology and Biochemistry 35, 453-461.

Matson PA (1997) Agricultural intensification and ecosystem properties. Science 277, 504-509.

Menalled FD, Gross KL \& Hammond M (2001) Weed aboveground and seedbank community responses to agricultural management systems. Ecological Applications 11, 1586-1601.

Miller ZJ \& Menalled FD (2015) Impact of species identity and phylogenetic relatedness on biologicallymediated plant-soil feedbacks in a low and a high intensity agroecosystem. Plant and Soil 389, 171183.

Nielsen DC, Unger PW \& Miller PR (2005) Efficient water use in dryland cropping systems in the Great Plains. Agronomy Journal 97, 364-372.

Oksanen L, Sammul M \& Mägi M (2006) On the indices of plant-plant competition and their pitfalls. Oikos 112, 149155.

Pollnac FW, Rew LJ, Maxwell BD \& Menalled FD (2008) Spatial patterns, species richness and cover in weed communities of organic and conventional no-tillage spring wheat systems. Weed Research 48, 398-407.

Pollnac FW, Maxwell BD \& Menalled FD (2009) Using species-area curves to examine weed communities in organic and conventional spring wheat systems. Weed Science 57, 241-247.

Postma-Blaaum MB, de Goede RGM, Bloem J, Faber JH \& BRUSSAARD L (2010) Soil biota community structure and abundance under agricultural intensification and extensification. Ecology 91, 460-473.

Powles SB \& YU Q (2010) Evolution in action: plants resistant to herbicides. Annual Review of Plant Biology 61, 317-347.

R Core Team (2013) R: A Language and Environment for Statistical Computing. R Foundation for Statistical Computing, Vienna, Austria.

Reynolds HL, Packer A, Bever JD \& Clay K (2003) Grassroots ecology: plant microbe soil interactions as drivers of plant community structure and dynamics. Ecology 84, 2281-2291.

Ryan MR, Smith RG, Mortensen DA et al. (2009) Weed crop competition relationships differ between organic and conventional cropping systems. Weed Research $\mathbf{4 9}$, $572-580$.

Ryan MR, Mortensen DA, BastiaAns L et al. (2010)

Elucidating the apparent maize tolerance to weed competition in long-term organically managed systems. Weed Research 50, 25-36.

Smith RG, Mortensen DA \& Ryan MR (2010) A new hypothesis for the functional role of diversity in mediating resource pools and weed-crop competition in agroecosystems. Weed Research 50, 37-48.

Smith RG, Ryan MR, Menalled FD, Hatfield JL \& Sauer TJ (2011) Direct and Indirect Impacts of Weed Management Practices on Soil Quality. ACSESS publications Soil Science Society of America, Madison, WI, USA.

Thakur MP, Milcu A, Manning P et al. (2015) Plant diversity drives soil microbial biomass carbon in grasslands irrespective of global environmental change factors. Global Change Biology 11, 4076-4085.

Ward SM, Cousens RD, Bagavathiannan MV et al. (2014) Agricultural weed research: a critique and two proposals. Weed Science 62, 672-678.

Wardle DA, Bardgett RD, Klironomos JN, Setala H, van der Putten WH \& Wall DH (2004) Ecological linkages between aboveground and belowground biota. Science 304, 1629-1633.

Wiскнам H (2009) ggplot2: Elegant Graphics for Data Analysis. Springer, New York.

Wolfe BE \& Klironomos JN (2005) Breaking new ground: soil communities and exotic plant invasion. BioScience $\mathbf{5 5}$, $477-487$.

Wortman SE, Francis CA, Bernards MA, Blankenship EE \& LindQuist JL (2013) Mechanical termination of diverse cover crop mixtures for improved weed suppression in organic cropping systems. Weed Science 61, 162-170.

Zak DR, Holmes WE, White DC, Peacock AD \& Tilman D (2003) Plant diversity, soil microbial communities, and ecosystem function: are there any links? Ecology 84, 20422050 .

\section{Supporting Information}

Additional Supporting Information may be found in the online version of this article:

Fig. S1 Site locations for pairs of organic and conventional farms sampled in Montana, USA, for soil inoculum used to assess the impacts of biotic plant-soil feedbacks on crop growth and crop-weed competition.

Table S1 Site descriptions for farms sampled. 